\title{
The effect of inhaled mannitol on bronchial mucus clearance in cystic fibrosis patients: a pilot study
}

\author{
M. Robinson*, E. Daviskas*, S. Eberl**, J. Baker*, H-K. Chan ${ }^{+}$, S.D. Anderson*, P.T.P. Bye*
}

The effect of inhaled mannitol in bronchial mucus clearance on cystic fibrosis patients: a pilot study. M. Robinson, E. Daviskas, S. Eberl, J. Baker, H-K. Chan, S.D. Anderson, P.T.P. Bye. (C) ERS Journals Ltd 1999.

ABSTRACT: It has been postulated that hypertonic saline (HS) might impair the antimicrobial effects of defensins within the airways. Alternative non-ionic osmotic agents such as mannitol may thus be preferable to HS in promoting bronchial mucus clearance (BMC) in patients with cystic fibrosis (CF).

This study reports the effect of inhalation of another osmotic agent, dry powder Mannitol (300 mg), compared with its control (empty capsules plus matched voluntary cough) and a $6 \%$ solution of HS on BMC in 12 patients with cystic fibrosis (CF).

Mucus clearance was measured using a radioaerosol/gamma camera technique. Post-intervention clearance was measured for $60 \mathrm{~min}$, followed by cough clearance for $30 \mathrm{~min}$.

Neither mannitol nor HS improved BMC during the actual intervention period compared with their respective controls. However during the post-intervention measurement there was a significant improvement in BMC for both the mannitol $(8.7 \pm 3.3 \%$ versus $2.8 \pm 0.7 \%)$ and HS $(10.0 \pm 2.3 \%$ versus $3.5 \pm 0.8 \%)$. There was also a significant improvement in cough clearance with the Mannitol $(9.7 \pm 2.4 \%)$ compared with its control $(2.5 \pm 0.8 \%)$. Despite premedication with a bronchodilator, a small fall in forced expiratory volume in one second (FEV1) was seen immediately after administration of both the mannitol $(7.3 \pm 2.5 \%)$ and HS $(5.8 \pm 1.2 \%)$. Values of FEV1 returned to baseline by the end of the study.

Inhaled mannitol is a potential mucoactive agent in cystic fibrosis patients. Further studies are required to establish the optimal dose and the long-term effectiveness of mannitol.

Eur Respir J 1999; 14: 678-685.

\begin{abstract}
*Respiratory Investigation Unit, Royal Prince Alfred Hospital, Sydney, Australia. **Dept of PET \& Nuclear Medicine, Royal Prince Alfred Hospital, Sydney, Australia. 'Dept. of Pharmacy, University of Sydney, Sydney, Australia.
\end{abstract}

Correspondence: M. Robinson

Respiratory Investigation Unit Level 10

Page Chest Pavilion

Royal Prince Alfred Hospital

Missenden Road

Camperdown

NSW

Australia, 2050

Fax: 61295158196

Keywords: Cystic fibrosis

hypertonic saline

mannitol

mucociliary clearance

Received: June 181998

Accepted after revision April 71999

This study was supported by the National Health \& Medical Research Council of Australia and Australian Cystic Fibrosis Research Trust.
A definitive understanding of the pathophysiological mechanisms underlying the lung disease in cystic fibrosis remains elusive [1-3]. Proponents of the so-called "isotonic volume/mucus clearance model" favour a cystic fibrosis (CF) epithelium characterized by the hyperabsorption of $\mathrm{Na}^{+}$ions failure of $\mathrm{Cl}^{-}$conductance and consequent accelerated isotonic volume resorption from the mucosal to the luminal surface [2]. This results in volume depletion of the periciliary fluid compartment dehydration of airway secretions impaction of mucus plaques on cilia and failure of mucus transport up the mucociliary escalator. Within this model, the removal of hyperviscous secretions remains one of the main goals in CE treatment and the supplemental nebulization of a hypertonic saline (HS) solution would seem a logical therapy. It has previously been shown that HS improves bronchial mucus clearance (BMC) in these patients [4] and that this effect is dose dependent [5]. Furthermore ENG et al. [6] have reported that a 2 week course of nebulized $\mathrm{HS}(10 \mathrm{~mL} \times$ $6 \%$ b.i.d.) improves forced expiratory volume in one second (FEV1) by $12.2 \%$ compared with control $(\mathrm{p}=0.004)$. One likely mechanism by which the HS works, is the creation of an osmotic gradient across the airway epithe- lium with the consequent movement of water into the airway lumen. This would then improve the biorheology of the secretions leading to their enhanced clearance.

SMith et al. [7] and Goldman et al. [8] have recently demonstrated a possible alternative link between the CF ionic milieu and the chronic recurrent infections that characterize this disease ("hypotonic/defensin model"). These investigators propose that the airway surface fluid (ASF) in CF is in fact high in $\mathrm{Na}^{+}$and $\mathrm{Cl}^{-}$and this leads to the deactivation of a series of cationic antimicrobial peptides known as defensins. Failure of the defensin system to eliminate bacteria would lead to a secondary cascade of inflammatory reactions characterized by the migration of a large number of neutrophils into the lung. Within this model it would be advantageous to use an alternative, nonionic, osmotic agent in preference to hypertonic saline. WILLs et al. [9] have reported that other osmotic agents (such as mannitol (MANN) and glucose) improve the tracheal mucus velocity of $\mathrm{CF}$ sputum placed on the bovine trachea. In this study the authors report the effect of mannitol, delivered by inhalation as a dry powder, on bronchial mucus clearance in a group of $\mathrm{CF}$ patients. 


\section{Materials and methods}

\section{Subjects}

The study group consisted of 12 adult patients with cystic fibrosis. A summary of their anthropometric and lung function data is presented in table 1 . All patients were studied when clinically stable. Any patients experiencing an infective exacerbation during the course of the study period were treated with antibiotics and recommenced the study a minimum of 10 days (oral or nebulized) or 14 days (intravenous) after cessation of the antibiotics. All other medications were kept constant throughout the study period, with the exception of one patient who commenced long-term nebulized tobramycin $(80 \mathrm{mg} \mathrm{b.i.d}$ ) after an exacerbation half way through the study. Six of the patients were on recombinant deoxyribonuclease (rhDNase), but did not take their rhDNase for at least $12 \mathrm{~h}$ prior to the study. Three of the patients also had a diagnosis of bronchial hyperresponsiveness. Ten of the 12 patients were colonized with Pseudomonas aeruginosa, 7 had Stapylocococcus aureus (including the two patients without $P$. aeruginosa) and 4 had Aspergillus fumigatus. Patients were instructed not to take any bronchodilators, exercise or perform physiotherapy on the morning of each of the study days. The study protocol was approved by the Hospital Ethics Review Committee and written informed consent was obtained from all patients prior to the study.

\section{Study design}

BMC was measured using a radioaerosol and gamma camera technique. Although the main aim of the study was to compare the effect of MANN on BMC with its control, HS (and its control) were included as an additional comparator. HS has a well-documented effect on BMC in this patient group [4-6]. Thus there were four study days: 1) mannitol, $300 \mathrm{mg}$ encapsulated dry powder; 2) mannitolcontrol (MANN-Cx), empty capsules with matched voluntary cough; 3) hypertonic Saline (HS): $7.0 \mathrm{~mL} \times 6.0 \%$ solution of $\mathrm{NaCl}$; 4) Hypertonic Saline-control (HS-Cx): $7.0 \mathrm{~mL} \times 0.9 \%$ solution of $\mathrm{NaCl}$ plus matched voluntary cough.

As both the MANN and HS are known to induce coughing in some patients, both control days consisted of inhalation of the intervention with matched cough. The

Table 1. - Anthropometric and lung function data (mean \pm $\mathrm{SD})$ for the 12 patients with cystic fibrosis in this study

\begin{tabular}{lcl}
\hline & Mean & Range \\
\hline Sex M/F & $5 / 7$ & \\
Age yrs & $29.9 \pm 9.4$ & $16-46$ \\
BMI kg.m ${ }^{-2}$ & $21.0 \pm 1.8$ & $18-24$ \\
FEV1 \% pred & $60.2 \pm 16.5$ & $42-87$ \\
FVC \% pred & $78.8 \pm 16.5$ & $47-102$ \\
FEV1/FVC \% & $65.4 \pm 12.9$ & $48-90$ \\
FEF25-75 \% pred & $32.5 \pm 21.1$ & $11-77$ \\
\hline
\end{tabular}

Lung function data are the mean values for all study days. M: male; F: female; BMI: body mass index; FEV1: forced expiratory volume in one second; FVC: forced vital capacity; FEF2575: forced expiratory flow between $25-75 \%$ of FVC. coughs were matched in terms of number and timing and consisted of a combination of spontaneous coughs topped up with voluntary coughs as required. Therefore, each control day was scheduled after its respective active day.

Patients were initially randomized to receive either the MANN or HS. On the second day they were randomized to either the remaining active or the control for the first day. On the third day they were randomized to receive either the remaining active or either of the controls. The final day was the remaining control. The studies were coded such that the investigators were blinded to the identity of the intervention at the time of data analysis.

\section{Preparation of mannitol}

The MANN powder (Mannitol BP; Rhône Poulenc Chemicals Pty Ltd, Brookvale, Australia) was prepared by spray drying (Buchi 190 Mini Spray Drier; Buchi, Flauvel, Switzerland) a solution containing $50 \mathrm{mg} \cdot \mathrm{mL}^{-1}$ of MANN. It was then sterilised by irradiation (Steritech, Wetherill Park, Australia) and a bioburden analysis performed (Stamford Laboratory, Ryde, Australia). Gelatine capsules (Parke-Davis, Sydney, Australia) were hand-filled with 10 and $20 \pm 0.2 \mathrm{mg}$ of MANN on an analytical balance (Sartorius BA11OS, Gottingen, Germany) under controlled conditions.

The particle size of the MANN was measured using a multi-stage liquid impinger (Astra Pharmaceuticals, Lund, Sweden) and assayed by vapour pressure osmometry (Knauer, Berlin, Germany). Forty-five per cent of particles by mass were $<5.3 \mu \mathrm{m}$ at $90 \mathrm{~L} \cdot \mathrm{min}^{-1}$.

\section{Drug delivery systems}

The mannitol was inhaled using a low resistance device Dinkihaler (Rhône Poulenc Rorer, Collegeville, PA, USA). Patients inhaled the MANN using a vital capacity manoeuvre with an inspiratory flow rate between 60-90 L. $\mathrm{min}^{-1}$ and a $5 \mathrm{~s}$ breath hold. The hypertonic and isotonic saline solutions were delivered via an Omron-NE-U06 domiciliary ultrasonic nebulizer (Omron Corporation, Tokyo, Japan) using normal tidal breathing. This nebulizer has a high volume output $\left(1.5 \mathrm{~mL} \cdot \mathrm{min}^{-1}\right)$ and a small dead volume $(0.5 \mathrm{~mL})$. The nebulizer was connected by a 115 $\mathrm{mL}$ piece of corrugated tubing to a $320 \mathrm{~mL}$ spacer device (Breath-A-Tech; Scott-Dibben, Newcastle, Australia). The spacer contained a one-way valve that prevented the patient exhaling back through the nebulizer. The mass median aerodynamic diameter (MMAD) of this delivery system without the valve was $3.7 \mu \mathrm{m}$ and $73 \%$ of the particles were less than $5 \mu \mathrm{m}$ (Malvern Mastersizer-X; Malvern, Worcestershire, UK) at ambient temperature $\left(22^{\circ} \mathrm{C}\right)$, pressure $101.5 \mathrm{kPa}(763 \mathrm{mmHg})$ and relative humidity (65\%). The tubing and spacer acted as a reservoir and minimized the deposition of large particles in the oropharynx, which may have caused additional throat irritation. The nebulizer was charged with $7.0 \mathrm{~mL}$ of the trial solution and inhaled to dryness using a tidal breathing pattern over a period of $\sim 6 \mathrm{~min}$.

The dose of MANN, HS and their controls leaving the respective delivery system on each study day was calculated using a mass balance technique (Sartorius Analytical Balance; BA110S, Gottingen, Germany). 


\section{Study protocol}

Both MANN and HS are known to induce airway narrowing in patients with bronchial hyperresponsiveness. As patients did not undergo bronchoprovocation testings as part of the study protocol, all patients inhaled a bronchodilator $(1,000 \mu \mathrm{g}$ Terbutaline Sulphate via a Turbuhaler ${ }^{\mathrm{TM}}$, Astra Pharmaceuticals, Lund, Sweden) prior to inhalation of the radioaerosol. Terbutaline does not increase mucociliary clearance in patients with CF [10].

After inhaling the radioaerosol, baseline clearance was measured for $15 \mathrm{~min}$ to assure that clearance was reproducible within patients between study days. The patient was then given the intervention over a $10 \mathrm{~min}$ period (total intervention period was $30 \mathrm{~min}$ ) before being repositioned under the gamma camera for the post-intervention clearance measurement for a further $60 \mathrm{~min}$. At the end of this period, cough clearance was measured by requesting the patient to voluntarily cough 100 times over the next 30 min.

In order to assess any possible airway narrowing induced by the interventions, the patient's spirometry was measured in triplicate (Minato AS600 Autospiro; Minato, Osaka, Japan) immediately prior to the intervention, $5 \mathrm{~min}$ after the end of the intervention and at the end of the study.

\section{Visual analogue scales}

Whenever spirometry was performed, the patient also completed a visual analogue scale (VAS). This was modified after MARKS et al. [11] and consisted of a series of 6 horizontal $10 \mathrm{~cm}$ lines labelled "no symptoms" and "worst I can imagine" at either extreme. The patient was requested to place a vertical line through the scale at the point that best represented the severity of their symptoms at that time point. The domains covered were; "chest tightness", "difficulty in breathing", "wheeze", "need to cough", "throat irritation" and "gagging response".

\section{Measurement of bronchial mucus clearance}

Bronchial mucus clearance was measured using the methods previously reported [12]. The patient was connected to a closed breathing circuit and inhaled the radioisotope $\left({ }^{99 \mathrm{~m}} \mathrm{Tc}\right.$-sulphur colloid; Chedoke-McMaster Nuclear Pharmacy, Hamilton, Ontario) [13]. The radioaerosol was generated using an Acorn nebulizer and had an MMAD of $5.5 \mu \mathrm{m}$ and span of 1.7 at $8.0 \mathrm{~L} \cdot \mathrm{min}^{-1}$ (Malvern Mastersizer-X; Malvern). The patient was requested to follow a preprogrammed breathing pattern that featured a mean inspiratory flow of $56.0 \mathrm{~L} \cdot \mathrm{min}^{-1}$ and a small tidal volume $(0.45 \mathrm{~L})$ [13]. This pattern is known to promote deposition of the radioaerosol predominantly in the ciliated airways. The breathing circuit provides a breath-by-breath analysis of the patient's breathing pattern.

Following inhalation of the radioaerosol, patients were placed supine on the scan bed under the gamma camera. With the exception of the cough clearance measurement, patients were requested to suppress their cough whenever possible throughout the study. A deposition scan was initially obtained by simultaneous acquisition of emission and transmission images using a scanning line source [14]. The transmission images were subsequently used to define the lung contour and peripheral and central regions of interest according to fixed ratios [15]. Deposition of the radioaerosol was defined in terms of the penetration index (the ratio of mean counts per pixel in the peripheral region to mean counts per pixel in the central region).

Dynamic data collection commenced exactly $10 \mathrm{~min}$ post-inhalation of the radioaerosol. Data were acquired in a large field of view gamma camera fitted with a low energy all purpose collimator (Phillips Diagnost Tomo; Hamburg, Germany). Alternating $20 \mathrm{~s}$ anterior and posterior images were collected each minute (allowing $20 \mathrm{~s}$ for camera rotation) and a dynamic geometric mean data set was subsequently generated [16].

\section{Data analysis}

No attempt was made to correct for background radiation as this is known to be less than $1 \%$ in the laboratory, with background counts typically around 10-15 counts per second (cps) and lung counts typically between 2000$4000 \mathrm{cps}$. All counts were corrected for radioactive decay to the start of the baseline acquisition. Bronchial mucus clearance was defined as the rate of removal of radioactivity from the right lung. The geometric mean data set was used to generate the time-activity curves. To remove any influence of variations in baseline clearance between individuals and within individuals between study days, the amount of activity remaining at the start of the intervention period was standardized at $100 \%$ and all curves normalized with reference to this point. The amount of activity cleared from the right lung during the baseline measurement, intervention period, post-intervention period, cough clearance measurement and the total amount cleared throughout the entire study was then calculated. Clearance was also calculated for the central and peripheral regions of the right lung as for the whole lung.

\section{Statistical analysis}

Comparison of interventions was performed using a one or two factor repeated measures analysis of variance (ANOVA). Post-hoc analysis was performed using the Fisher PLSD test [17]. A computerized statistical package was used to perform all statistical analyses (Statview; Abacus Concepts Inc., Berkeley, CA, USA). Significance was taken as $\mathrm{p} \leq 0.05$.

\section{Results}

There was no significant difference in initial deposition of the radioaerosol, as assessed by mean penetration index or per cent deposited by region, on any of the study days $(\mathrm{p}=0.2)$. Mean baseline clearance ranged $5.3-5.8 \%$ over the $15 \mathrm{~min}$ period and was not statistically different between study days $(\mathrm{p}=0.8)$.

The normalized mean time-activity curves are shown in figure 1 . There was no difference in clearance with any of the interventions during the actual intervention period $(p=0.8)$. There was a statistically significant improvement in $\mathrm{BMC}$ during the $60 \mathrm{~min}$ post-intervention clearance 


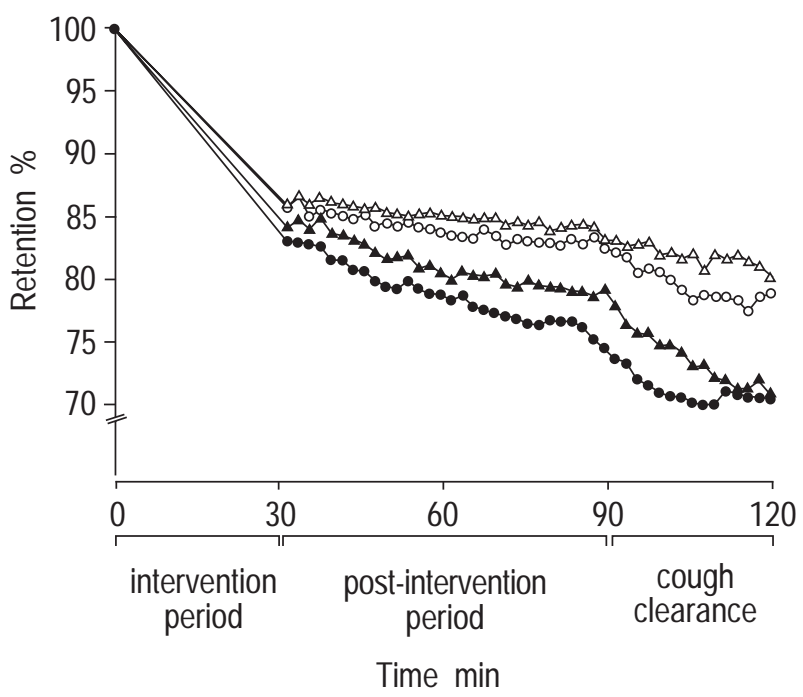

Fig. 1. - Mean mucus clearance curves for all study days. $\triangle$ : mannitol control; $\bigcirc$ : hypertonic saline control; $\mathbf{\Delta}$ : mannitol; $\bigcirc$ : hypertonic saline. The active curves $(\boldsymbol{\Lambda}, \boldsymbol{O})$ are significantly different from their respective control curves.

measurement for both the MANN $(8.7 \pm 3.3 \%)$ and HS $(10.0 \pm 2.3 \%)$ compared with their controls $(2.8 \pm 0.7 \%$ and $3.5 \pm 0.8 \%$ respectively), $\mathrm{p}=0.01$ (table 2 ). For the MANN only, there was an additional improvement in BMC during the cough clearance measurement $(9.7 \pm 2.4 \%$ versus $2.5 \pm 0.8 \%, \mathrm{p}=0.001)$. By the end of the study there were also significant improvements in the total amounts cleared for the MANN (27.6 $\pm 3.7 \%)$ and HS $(31.0 \pm 5.5 \%)$ interventions compared with their controls $(18.6 \pm 3.8 \%$ and $20.9 \pm 3.6 \%$ respectively, $p=0.007)$. The only change in regional clearance was seen in the peripheral region of the lung during the post-intervention clearance measurement. The peripheral clearance with MANN $(23.2 \pm 2.6 \%)$ and the HS $(17.1 \pm 5.4 \%)$ was significantly better than their controls $(2.6 \pm 3.1 \%$ and $6.6 \pm 6.1 \%$ respectively, $p=0.001)$. There was no difference in the response of the patients taking rhDNase compared with those not on the drug $(\mathrm{p}=0.1)$.

The mean inhaled weight of MANN was $267.5 \pm 17.0$ $\mathrm{mg}(89.2 \%$ of the loaded dose). The mean time to deliver this dose was $12.3 \pm 1.8 \min (10.22 \pm 2.5$ for MANN-Cx).

Table 2. - Mean \pm SEM values for bronchial mucus clearance $(\%)$ during the intervention period, the post-intervention clearance measurement and the cough clearance measurement

\begin{tabular}{lcccc}
\hline & $\begin{array}{c}\text { Inter- } \\
\text { vention } \\
\text { period } \\
(30 \mathrm{~min})\end{array}$ & $\begin{array}{c}\text { Post- } \\
\text { intervention } \\
\text { clearance } \\
(60 \mathrm{~min})\end{array}$ & $\begin{array}{c}\text { Cough } \\
\text { clearance } \\
(30 \mathrm{~min})\end{array}$ & $\begin{array}{c}\text { Total } \\
\text { clearance to } \\
\text { end of study } \\
(120 \mathrm{~min})\end{array}$ \\
\hline MANN & $14.2 \pm 1.8$ & $8.7 \pm 3.3^{*}$ & $9.7 \pm 2.4^{*}$ & $27.6 \pm 3.7^{*}$ \\
MANN-Cx & $14.1 \pm 3.2$ & $2.8 \pm 0.7$ & $2.5 \pm 0.8$ & $18.6 \pm 3.8$ \\
HS & $15.7 \pm 3.7$ & $10.0 \pm 2.3^{*}$ & $9.9 \pm 2.7$ & $31.0 \pm 5.5^{*}$ \\
HS-Cx & $13.5 \pm 9.7$ & $3.5 \pm 0.8$ & $6.1 \pm 1.6$ & $20.9 \pm 3.6$ \\
\hline
\end{tabular}

The times in parentheses indicate duration of acquisition of clearance data. $*$ : significantly different from respective control day $(\mathrm{p}<0.01)$. There was no difference when mannitol (MANN) was compared with hypertonic saline (HS). Cx: control.
The mean inhaled volume of the HS solution was $4.43 \pm$ $0.42 \mathrm{~mL}(265.8 \mathrm{mg} \mathrm{NaCl})$ over $6.2 \pm 1.2 \mathrm{~min}$. This was not significantly different from its control $(4.51 \pm 0.5 \mathrm{~mL}$ over $5.8 \pm 0.6$ min, $\mathrm{p}=0.4$ ).

During the intervention period with both the MANN-Cx and HS-Cx it was aimed to have the patient cough a number of times equal to or slightly greater than the number recorded on their respective active days. However, in some individuals the targets were quite high and some patients found it difficult to voluntarily match the target number. This was especially true for the MANN, where the mean number of coughs recorded during the half hour intervention was $133 \pm 23$. Although this number was not significantly more than its control $(115.8 \pm 19.5, \mathrm{p}=0.2)$, it was significantly more than the number recorded with the HS $(99.5 \pm 17.8, p=0.04)$. The number of coughs recorded during the post-intervention $\mathrm{BMC}$ and cough clearance measurements was well matched in all study days and is detailed in table 3 .

There was no significant variation in mean baseline lung function between any of the study days $(\mathrm{FEV} 1, \mathrm{p}=0.6)$. Changes in FEV1 with each of the interventions are shown in table 4. Despite the fact that patients had been premedicated with a bronchodilator $\sim 55$ min prior to inhaling the interventions, small decreases in mean FEV1 were seen with MANN (-7.3 $\pm 2.5 \%)$ and HS $(-5.8 \pm 1.2 \%)$. Both of these falls were significantly different from their respective controls $(\mathrm{p}=0.004)$ but not from each other. The FEV1 had all but returned to its pre-intervention value by the end of the study, 95 min later.

The only differences in the VAS were recorded for "need to cough" (both MANN and HS different from their control days but not from each other, $\mathrm{p}=0.006$ ) and "throat irritation" (HS versus HS-Cx, $\mathrm{p}=0.02$ ) pre- and postintervention. However, these had returned to their preintervention values by the end of the study.

\section{Discussion}

This is the first report to the authors' knowledge of an increase in $\mathrm{BMC}$ following the inhalation of dry powder MANN in patients with CF. The improvements seen with MANN were of a similar magnitude to those seen with a $6 \%$ solution of hypertonic saline. The latter is known to increase BMC $[4,5]$ and to improve lung function in $\mathrm{CF}$ patients over a 2 week period [6].

Table 3. - Mean \pm SEM number of coughs recorded during the intervention period, post intervention bronchial mucus clearance measurement and cough clearance measurement

\begin{tabular}{lccc}
\hline & $\begin{array}{c}\text { Intervention } \\
\text { period } \\
\text { coughs }\end{array}$ & $\begin{array}{c}\text { Post- } \\
\text { intervention } \\
\text { BMC coughs }\end{array}$ & $\begin{array}{c}\text { Cough } \\
\text { clearance } \\
\text { coughs }\end{array}$ \\
\hline MANN & $133 \pm 22.9^{*}$ & $12.7 \pm 4.1$ & $112.6 \pm 5.4$ \\
MANN-Cx & $115.8 \pm 19.5$ & $15.0 \pm 4.3$ & $114.4 \pm 5.6$ \\
HS & $99.5 \pm 17.8$ & $9.3 \pm 2.9$ & $112.0 \pm 5.8$ \\
HS-Cx & $96.0 \pm 17.9$ & $12.1 \pm 4.3$ & $115.4 \pm 6.8$ \\
\hline
\end{tabular}

The mean number of coughs recorded from the mannitol (MANN) inhalation was significantly higher than the number on the HS day $(\mathrm{p}=0.04)$. BMC: bronchial mucus clearance; MANN: mannitol; HS: hypertonic saline; $\mathrm{Cx}$ : control. 
Table 4. - Change in forced expiratory volume in one second (FEV 1$) 5$ min after inhalation of the intervention and at the end of the study (95 min later) expressed as a percentage change (mean \pm SEM) from the pre-intervention value

\begin{tabular}{lcc}
\hline & Intervention & End of study \\
\hline MANN & $-7.3 \pm 2.5^{*}$ & $-1.8 \pm 2.7$ \\
MANN-Cx & $0.5 \pm 0.9$ & $-2.2 \pm 1.0$ \\
HS & $-5.8 \pm 1.2^{*}$ & $-2.0 \pm 0.7$ \\
HS-Cx & $-0.6 \pm 2.3$ & $-0.6 \pm 2.1$ \\
\hline
\end{tabular}

*: significantly different from respective control $(\mathrm{p}=0.004)$. MANN: mannitol; HS: hypertonic saline; Cx: control.

Based on previous cross-sectional studies and the variance of measurement in reproducibility studies, the investigators regard an improvement in BMC of 10 absolute percentage points in $60 \mathrm{~min}$ as being clinically relevant [12]. An improvement in clearance of $10 \%$ was basically achieved in this study with both the MANN and HS at each phase of the study (i.e. during the intervention period, the post-intervention clearance and cough clearance measurement). The mean total clearance throughout the entire study was $\sim 30 \%$ for both interventions compared with $20 \%$ for the controls. It is likely that both controls in this study had some positive effects on BMC. DAVISKAs et al. [18] have shown that inhalation of a solution of $0.9 \%$ can cause a small improvement in BMC compared with baseline in both normal subjects and asthmatics. Several investigators have shown that cough is an effective mechanism for clearing airway secretions in diseases characterized by mucus hypersecretion or impaired mucociliary clearance (including CF) [19, 20]. Thus the voluntary coughing incorporated on both control days in this study is likely to have increased BMC and in so doing diminished any differences between the active interventions and controls. It is anticipated that an even greater improvement in BMC would have been seen with both MANN and HS over resting baseline clearance, where cough would not be so pronounced.

In two separate studies, DAVISKAS and coworkers [18, 21] have shown that inhalation of MANN results in a doubling of BMC in healthy subjects (400 mg MANN), asthmatics (267 $\pm 171 \mathrm{mg})$ [18] and patients with bronchiectasis $(320 \pm 81 \mathrm{mg})$ [21] compared with control. Significant improvements were also seen in the central, intermediate and peripheral regions of the lung in the healthy subjects and asthmatics and in the central and intermediate regions in the bronchiectatic patients. In contrast to the current study, most of the increase in clearance in the studies of DAVISKAS et al. $[18,21]$ occurred during the actual intervention period. This has also been the current authors' experience with previous trials looking at the effect of HS on BMC in CF patients [22]. The reason for the difference in the current study is not known. It is unlikely to be related to differences in deposition of the radioaerosol as this was similar in all studies. It is also unlikely to be due to the amount of MANN or HS depositing on the airway or the site of deposition, as the same delivery devices and similar doses of both interventions were used in this and previous studies. It may have been due to the large number of coughs recorded during the intervention period on all days. This may have lead to the mucociliary/cough clearance mechanisms functioning close to their maximum capacity during the intervention period with all interventions including the controls.

The diminished response to MANN in the patients with CF compared with those with bronchiectasis may be related to overall mucus load. Both diseases are characterized by the presence of bronchiectactic lesions, mucus hypersecretion and chronic recurrent infection. In the study of DAVISKAS et al. [21] the bronchiectatic lesions were confined to one or two lung lobes and lung function was relatively preserved. Despite the younger age of the study population in the current study, the lung pathology was more widespread and all but one patient had evidence of airflow limitation. Thus a higher dose of MANN may be required to affect the same change in airway osmolarity and/or mucus rheology in patients with CF.

There are several mechanisms whereby the MANN and HS may be acting to improve BMC. Both agents are known to induce an influx of water into the airway lumen and as such improve hydration of airway secretions [2325]. Even in normal subjects, increased hydration of airway secretions is known to increase mucociliary clearance [26]. In nasal challenges, 10-s exposure to a hyperosmolar MANN solution $\left(869 \pm 8 \mathrm{mOsm} \cdot \mathrm{kg}^{-1}\right)$ resulted in a marked liquid shift into the nasal lumen with a corresponding $7 \%$ fall in the osmolality of the lavage fluid (down to $809 \mathrm{mOsm} \cdot \mathrm{kg}^{-1}$ ) [27]. These authors note that the hyperosmolar challenge did not appear to be associated with increases in vascular permeability as there were no corresponding changes in serum albumin in lavage solutions. This has also been confirmed in ferret tracheal preparations [24] and in anaesthetized guineapigs [28]. In the latter study, tracheal mucus velocity was transiently increased by $122 \%$ following the nebulization of a $14.4 \%$ solution of hypertonic saline, but no increase in plasma protein extravasation was detected.

Further evidence for the effectiveness of hypertonic solutions in removing airway secretions comes from the work of WinTERs et al. [23] in anaesthetised dogs. These investigators measured ciliary beat frequency (CBF), tracheal mucus velocity (TMV) and BMC following 90 min of continuous nebulization of a $5 \%$ and a $20 \%$ solution of hypertonic saline. CBF and TMV were markedly increased by inhalation of both $5 \%$ and $20 \%$ HS. In contrast, BMC increased with $20 \%$ HS and decreased slightly following $5 \%$ HS. The effects of hypertonic solutions were even greater when equimolar solutions containing ions of lower permeability were substituted for the $\mathrm{NaCl}$. The authors concluded that both improved mucuscilia coupling and enhanced clearance may be achieved by the hydration of the airway lumen by using an aqueous hypertonic aerosol.

As well as the effect on hydration of secretions, both MANN and HS may have a direct effect on the mucus macromolecule resulting in improvements in mucus biorheology. FENG et al. [29] propose that the $\mathrm{Na}^{+}$ions shield the fixed negative charges along the macromolecular core of the mucin polymer. This substantially reduces the size of the macromolecular coils and decreases intermolecular interactions, both of which will reduce the number of entanglements with neighbouring macromolecules. This would lower both the viscosity and the elasticity of the mucus. Nonionic agents such as MANN are also believed 
to reduce the entanglement density, but are more likely to do so by substituting for the oligosaccharide moieties linked to the high molecular weight mucin peptides thus disrupting hydrogen bonds between mucin [29].

This effect of MANN and HS on mucus rheology is supported by the data of WILLs et al. [9]. Using a mucusdepleted bovine tracheal explant model, these investigators showed that the mucus transportability index improved from $29 \pm 3 \%-67 \pm 4 \%$ after overnight incubation of CF sputa with MANN to a final concentration of 100 $\mathrm{mM}$. Similar results had previously been shown by the same investigators when CF sputum was incubated with sufficient solid $\mathrm{NaCl}$ to increase its concentration by 90 $\mathrm{mM}$. As this was a closed system, there could not have been any change in the hydration of the sputum and the increase in mucus transportability was shown to be due to improvements in both viscosity and elasticity. They conclude that increasing the osmolality, rather than the hydration, of CF sputum may benefit people with cystic fibrosis by improving mucociliary transport.

In addition to direct effects on epithelial ion and water transport, hyperosmotic perturbations of the ASF may activate sensory nerves stimulating the release of neuropeptides, such as substance $\mathrm{P}$ or neurokinin $\mathrm{A}$, and the induction of neurogenic inflammation [23, 24]. Mediators such as histamine and prostaglandin F (PGF2 $\alpha$ ) may also be released from inflammatory cells in response to hyperosmotic stimulation and may further augment transepithelial water transport. Such mediator release might also activate adrenergic, cholinergic, peptidergic or other cell receptors to stimulate $\mathrm{CBF}[23,24]$.

Several investigators have demonstrated that hyperosmotic stimuli, including MANN and HS [24, 30] may act as secretagogues. This may be a direct effect of the stimulus on the mucus/serous secretory cells or an indirect effect through mediators that are released in response to hypersosmolarity and are known to stimulate mucus secretion [31]. Although increased mucus secretion would generally be regarded as undesirable in patients with hypersecretion such as in $\mathrm{CF}$, combined with increased $\mathrm{CBF}$, it may provide a mechanism of "flushing out" otherwise stagnant secretions ladened with bacteria and destructive proteolytic enzymes.

MANN offers several other potential benefits over HS. As it can be encapsulated and delivered as a dry powder, delivery times could potentially be decreased compared with a domiciliary nebulizer required for delivery of HS. This would also increase the portability and adherence to treatment. Delivery times for the MANN in the current study were actually increased compared with HS, but this was due to the decision to use $20 \mathrm{mg}$ capsule fills rather than $40 \mathrm{mg}$ fills. From previous studies, it appears that the effect of HS on BMC is only short-lived. This is likely to be due to the rapid efflux of water into the airway and the consequent reduction in the osmotic gradient and hyperosmotic stimulus [25]. This effect is compounded by the use of ions such as $\mathrm{Na}^{+}$and $\mathrm{Cl}^{-}$, that rapidly diffuse across the epithelial barrier. MANN crosses the intact epithelial barrier only very slowly [32] and as such might be expected to have a more prolonged osmotic effect. Studies in asthmatic subjects have shown that MANN is more potent in altering airway osmolarity than a $4.5 \%$ solution of HS [33].
The exact ionic composition of the airway surface liquid (ASL) in both health and disease is currently being debated $[2,3]$. Traditionally the $\mathrm{CF}$ airway epithelium was thought to exhibit both increased $\mathrm{Na}^{+}$absorption and decreased $\mathrm{Cl}^{-}$permeability. This resulted in the net flux of water from the luminal to the abluminal surface, with consequent depletion of the periciliary compartment, dehydration of respiratory secretions, mucus stasis, airway obstruction and infection [2]. Neutrophil phagocytosis of bacteria is also known to be deficient in low $\mathrm{Na}^{+}$environments [34]. Several strategies have been proposed to overcome this problem by increasing the $\mathrm{Na}^{+}[35]$ and/or the $\mathrm{Cl}^{-}$[36] content of CF ASL. The authors originally hypothesised direct nebulization of HS as a logical potential "replacement" therapy for CF patients within this model.

Recently, an alternative model has come into prominence. QuinTon et al. [37] have proposed that the forces that drive ion movement in the airway are similar to those in the sweat duct. That is, the failure of cystic fibrosis transmembrane conductance regulator (CFTR) chloride conductance results in failure to reabsorb $\mathrm{Cl}^{-}$from the airway lumen. This hypothesis is supported by experimental work demonstrating an increase in both $\mathrm{Na}^{+}$and $\mathrm{Cl}^{-}$concentrations in the $\mathrm{CF}$ ASL [3, 8]. Moreover, SMith et al. [7] and Goldman et al. [8] have shown that high salt concentrations deactivate a low molecular weight cationic peptide known as human $\beta$-defensin- 1 , which possesses antibacterial, antiviral and antifungal activity. These authors propose that the deactivation of the defensin molecules by the high salt concentration found in CF sputum leads to violation of the first line of the host defence system and the consequent recruitment of large numbers of neutrophils into the airways. Here, the degradative products of neutrophil activity (elastases, proteases, oxygen radicals, etc.) would cause ongoing lung damage and the contents of degenerative neutrophils deoxyribonucleic ((DNA), actin) would further increase mucus viscosity.

Within this alternative model the nebulization of HS may potentially be harmful and MANN would be a preferable mucoactive agent. However, the effect of high salt concentrations on defensins is reversible and, due to the rapid influx of water into the airway following nebulization of HS, the high salt concentration is likely to be very transient. It is believed that the effect that HS has on debulking the copious amounts of airway secretions is likely to be more important than the transient effect on defensins, especially in patients already colonized with bacteria. However, within this model MANN represents a viable alternative therapy, as it is known not to deactivate defensins. Furthermore, in this study the MANN and HS appear to be equally effective in promoting BMC, even though the dose of MANN used was only approximately one tenth of the osmotic strength of the HS.

MANN is virtually metabolically inert in humans. As it does not readily cross the airway epithelial barrier, it was hoped that the osmotic effect of MANN may be sustained for longer periods than the more readily diffusible ionic osmotic agents such as HS. However, it is also known that the presence of various $P$. aeruginosa exoproducts increases the permeability of cell monolayers to MANN permeability in tissue culture [38]. Thus the abundance of Pseudomonas exoproducts in CF sputum may have 
increased the permeability of the airway epithelium to MANN and diminished this effect.

Approximately $84 \%$ of $P$. aeruginosa isolates and $95 \%$ of Burkholderia cepacia isolates are able to utilize MANN as carbon and energy source. However, with the abundance of substrate already present in CF respiratory secretions it is unlikely that the presence of additional substrate will influence bacterial burden. This needs to be confirmed by quantitative microbiology.

Despite premedication with a bronchodilator, a small fall in FEV1 was seen in the patients following nebulization with both MANN and HS. However, this had largely reversed by the end of the study ( $95 \mathrm{~min}$ later). The authors believe that it is advisable to administer a bronchodilator prior to the inhalation of either MANN or HS in order to minimize any airway narrowing.

This paper confirms the utility of osmotic agents, such as mannitol and hypertonic saline, in improving bronchial mucus clearance in patients with cystic fibrosis. In general, both substances were equally efficacious in improving bronchial mucus clearance and well-tolerated by the patients with the main complaints being upper airway irritation and the consequent inducement of cough. The authors believe that these problems can be overcome by the development of more sophisticated delivery devices that minimize deposition in the hypopharynx. Further studies to optimize the dose of mannitol depositing on the intrathroracic airways are required before embarking on longer term clinical trials.

Acknowledgements. The authors wish to thank N. Chew for preparation of the mannitol powder and J. Brannan for his technical advice. The patents for the use of mannitol described in this manuscript are US patent No. 5,817,028, International Patent (PCT/AU95/00086) and Australian Patent No. 682756. All patents are owned by the Central Sydney Area Health Service.

\section{References}

1. Quinton PM. Viscosity versus composition in airway pathology. Editorial. Am J Respir Crit Care Med 1994; 149: 6-7.

2. Matsui H, Grubb BR, Tarran R, et al. Evidence for periciliary liquid layer depletion, not abnormal ion composition, in the pathogenesis of cystic fibrosis airways disease. Cell 1998; 95: 1005-1015.

3. Zabner J, Smith JJ, Karp PH, Widdicombe JH, Welsh MJ. Loss of CFTR chloride channels alters salt absorption by cystic fibrosis aiway epithelia in vitro. Mol Cell 1998; 2: 397-403.

4. Robinson M, Regnis JA, Bailey DL, King M, Bautovich GJ, Bye PT. Effect of hypertonic saline, amiloride, and cough on mucociliary clearance in patients with cystic fibrosis. Am J Respir Crit Care Med 1996; 153: 1503-1509.

5. Robinson M, Hemming AL, Regnis JA, et al. Effect of increasing doses of hypertonic saline on mucociliary clearance in patients with cystic fibrosis. Thorax 1997; 52: 900-903.

6. Eng PA, Morton J, Douglass JA, Riedler J, Wilson J, Robertson CF. Short-term efficacy of ultrasonically nebulized hypertonic saline in cystic fibrosis. Ped Pulmonol 1996; 21: 77-83.

7. Smith JJ, Travis SM, Greenberg EP, Welsh MJ. Cystic fibrosis airway epithelia fail to kill bacteria because of abnormal airway surface fluid. Cell 1996; 85: 229-236.

8. Goldman MJ, Anderson GM, Stolzenberg ED, Kari UP, Zasloff M, Wilson JM. Human $\beta$-defensin-1 is a saltsensitive antibiotic in lung that is inactivated in cystic fibrosis. Cell 1997; 88: 553-560.

9. Wills PJ, Chan WM, Hall RL, Cole PJ. Ciliary Transportability of Sputum is Governed by its Osmolality. In: Baum GL, Priel Z, Roth Y, Liron N, Ostfield EJ, eds. Cilia, Mucus and Mucociliary Interactions. New York, Marcel Dekker Inc, 1998; 281-284.

10. Mortensen J, Hansen A, Falk M, Kirketerp I, Groth S. Reduced effect of inhaled B2-adrenergic agonists on lung mucociliary clearance in patients with cystic fibrosis. Chest 1993; 103: 805-811.

11. Marks GB, Yates DH, Sist M, et al. Respiratory sensation during bronchial challenge testing with methacholine, sodium metabisulphite and adenosine monophosphate. Thorax 1996; 51: 793-798.

12. Regnis JA, Robinson M, Bailey DL, et al. Mucociliary clearance in patients with cystic fibrosis and in normal subjects. Am J Respir Crit Care Med 1994; 150: 66-71.

13. Phipps PR, Gonda I, Anderson SD. Apparatus for the control of breathing patterns during aerosol inhalation. $J$ Aerosol Med 1992; 5: 155-169.

14. Bailey DL, Robinson M, Meikle SR, Bye PTP. Simultaneous emission and transmission measurements as an adjunct to dynamic planar gamma camera studies. Eur $J$ Nuc Med 1996; 23: 326-331.

15. Phipps PR, Gonda I, Bailey DL, Borham P, Bautovich G, Anderson SD. Comparisons of planar and tomographic gamma scintigraphy to measure the penetration index of inhaled aerosols. Am Rev Respir Dis 1989; 139: 15161523.

16. Bailey DL, Fulton RR, Jackson CB, Hutton BF. Dynamic geometric mean studies using a single headed rotating gamma camera. J Nuc Med 1989; 30: 1865-1869.

17. Altman DG. Practical Statistics for Medical Research, first ed: Chapman \& Hall, London, 1991.

18. Daviskas E, Anderson SD, Gonda I, et al. Inhalation of hypertonic saline aerosol enhances mucociliary clearance in asthmatic and healthy subjects. Eur Respir $J$ 1996; 9: 725-732.

19. Rossman CM, Waldes OR, Sampson D, Newhouse MT. Effect of chest physiotherapy on the removal of mucus in patients with cystic fibrosis. Am Rev Respir Dis 1982; 126: 131-135.

20. Pavia D. Lung mucociliary clearance. In: Clarke SW, Pavia D, ed. Aerosols and the Lung. Boston: Butterworths, 1984; pp. 127-155.

21. Daviskas E, Anderson SD, Eberl S, Chan H-K, Bautovich G. Inhalation of dry powder mannitol inproves clearance of mucus in patients with bronchiectasis. Am J Respir Crit Care Med 1999; 159: 1843-1848.

22. Robinson M, Hemming AL, Regnis JA, et al. Improved mucociliary clearance following nebulisation with hypertonic saline in patients with cystic fibrosis. In: Baum GL, Priel Z, Roth Y, Liron N, Ostfield EJ, eds. Cilia, Mucus and Mucociliary Interactions. New York, Marcel Dekker Inc, 1998; 265-280.

23. Winters SL, Yeates DB. Roles of hydration, sodium, and chloride in regulation of canine mucociliary transport system. J Appl Physiol 1997; 83: 1360-1369.

24. Price AM, Webber SE, Widdicombe JG. Osmolality affects ion and water fluxes and secretion in the ferret trachea. J Appl Physiol 1993; 74: 2788-2794.

25. Folkesson HG, Kheradmand F, Matthay MA. The effect 
of salt water on alveolar epithelial barrier function. $A m \mathrm{~J}$ Respir Crit Care Med 1994; 150: 1555-1563.

26. Rubin BK, Ramirez O, Zayas G, Finegan B, King M. Respiratory mucus from asymptomatic smokers is better hydrated and more easily cleared by mucociliary action. Am Rev Respir Dis 1992; 145: 545-547.

27. Silber G, Proud D, Warner J, et al. In vivo release of inflammatory mediators by hyperosmolar solutions. $\mathrm{Am}$ Rev Respir Dis 1988; 137: 606-612.

28. Newton BB, Hall RL. Mucociliary clearance in the guinea pig is increased by ouabain (i.v.) and by hypertonic saline (14.4\%) aerosol. In: Baum GL, Priel Z, Roth Y, Liron N, Ostfield EJ, eds. Cilia, Mucus and Mucociliary Interactions. New York, Marcel Dekker Inc, 1998; 285-294.

29. Feng W, Garrett H, Speert DP, King M. Improved clearability of cystic fibrosis sputum with dextran treatement in vitro. Am J Respir Crit Care Med 1998; 157: 710-714.

30. Peatfield AC, Richardson PS, Wells UM. The effect of airflow on mucus secretion into the trachea of the cat. $J$ Physiol 1986; 380: 429-439.

31. Tavakoli S, Levine SJ, Shelhamer JH. Airway Mucus Secretion. In: Barnes PJ, Grunstein MM, Leff AR, Woolcock AJ, eds. Asthma. Philadelphia, Lippencott Raven Publishers, 1997; 843-857.
32. Yankaskas JR, Gatzy JT, Boucher RC. Effects of raised osmolarity on canine tracheal epithelial ion transport function. J Appl Physiol 1987; 62: 2241-2245.

33. Anderson SD, Brannan J, Spring J, et al. A new method for bronchial-provocation testing in asthmatic subjects using a dry powder of mannitol. Am J Respir Crit Care Med 1997; 156: 758-765.

34. Mizgerd JP, Kobzik L, Warner AE, Brain JD. Effects of sodium concentration on human neutrophil bactericidal functions. Am J Physiol 1995; 269: L388-393.

35. Hofmann T, Stutts MJ, Ziersch A, et al. Effects of topically delivered benzamil and amiloride on nasal potential difference in cystic fibrosis. Am J Respir Crit Care Med 1998; 157: 1844-1849.

36. Bennett WD, Olivier KN, Zeman KL, Hohnecker KW, Boucher RC, Knowles MR. Effect of Uridine 5'-Triphosphate plus amiloride on mucociliary clearance in adult cystic fibrosis. Am J Respir Crit Care Med 1996; 153: 1796-1801.

37. Quinton PM Cystic fibrosis: a disease in electrolyte transport. FASEB J 1990; 4: 2709-2717.

38. Azghani A. Pseudomonas aeruginosa and epithelial permeability: Role of virulence factors elastase and exotoxin A. Am J Respir Cell Mol Biol 1996; 15: 132-140. 